\title{
Las Finanzas Conductuales, el Alfabetismo Financiero y su Impacto en la Toma de Decisiones Financieras, el Bienestar Económico y la Felicidad.
}

The Behavioral Finance, the Financial Literacy and his Impact in the Capture of Financial Decisions, the Economic Well-being and the Happiness.

Flor de María Mendoza Austria ${ }^{a}$, Susana Elizabeth Martínez Franco ${ }^{b}$

\begin{abstract}
:
Currently for society and people, the issue of finances is significant, since in order to achieve their financial goals, decisions are made behaviorally, emotionally and sometimes irrationally, damaging the economic and social well-being of the environment; Therefore it is important to know through research that Behavioral Finance, Financial Literacy and its Impact on Financial Decision Making, Economic Wellbeing and Happiness, are issues that influence the individual to travel in everyday life.
\end{abstract}

Keywords:

Financial literacy, culture, economic well-being

\section{Resumen:}

En la actualidad para la sociedad y las personas el tema de las finanzas es significativo, ya que para lograr sus objetivos económicos se toman decisiones de forma conductual, emocional y en ocasiones de manera irracional, perjudicando el bienestar monetario y social del entorno; por lo anterior es importante conocer por medio de investigaciones que las Finanzas Conductuales, el Alfabetismo Financiero y su Impacto en la Toma de Decisiones Financieras, el Bienestar Económico y la Felicidad, son temas que influyen en el individuo para transitar en la vida cotidiana.

\section{Palabras Clave:}

Alfabetismo financiero, cultura, bienestar económico

\section{Introducción}

El presente artículo describe por medio de la investigación la importancia de tener habilidades y conocimientos financieros conocido como alfabetismo financiero y los factores psicológicos, culturales y emocionales que conllevan a enfrentar las necesidades básicas de consumo, inversión, ahorro y protección, que obliga a las personas a tomar decisiones de dinero, en ocasiones de forma conductual e irracional; por lo anterior el artículo "Las Finanzas Conductuales y el Alfabetismo Financiero para la Toma de Decisiones en la vida cotidiana, que genere un Bienestar Económico" es interesante y aporta a las personas la forma de actuar ante situaciones financieras habituales en la sociedad.

El autor menciona que la vida financiera del individuo tiene tres grandes etapas, en cada una de ellas los objetivos financieros y toma de decisiones son diferentes, ya que transitan los ingresos de dependencia 0 negativos y positivos 0 de independencia. 
La primera etapa comprende una edad hasta los 54 años lo que considera de "acumulación", aquí los objetivos se enfocan a reunir la mayor riqueza y la orientación de los objetivos, ésta época es la más larga para el hombre su preocupación está en la independencia financiera ya que se enfrenta al empleo, impuestos, matrimonio, renta, hipoteca, la adquisición de créditos para una casa o automóvil, la dependencia de los hijos, seguros de enfermedad, vida y retiro, entre otros aspectos.

La segunda etapa llega hasta los 65 años, llama de "consolidación" contempla a la persona de mediana edad donde sus ingresos ya están definidos, por trabajo y patrimonio acumulado en su vida, permitiéndole un ahorro y bienestar para su jubilación.

Por último de más de 65 años la etapa de "protección", que son las personas que han logrado su jubilación, con el complemento de sus ahorros o rendimientos generados por su patrimonio, siempre y cuando en las dos etapas anteriores realizó planes financieros.

La literatura utilizada en esta investigación parte de los conceptos de alfabetismo financiero y el punto de vista de la teoría económica, resaltando que los individuos deberán establecer sus prioridades y jerarquizar sus necesidades para poder solventar y manejar su dinero de manera eficiente. Los problemas económicos surgen por el escaso conocimiento en el alfabetismo financiero que se trasmite de generación en generación, así también por cuestiones culturales y sociales que influyen en el bienestar económico.

En el artículo se analizan autores como Adam Smith de quien se retoma el tema de bienestar económico, León Walras que hace un tratamiento matemático del beneficio deseado y es mejorado por John von Neuman y Oskar Morgenstern.
En la década de los 50 , se empieza a hablar sobre la teoría financiera, a la fecha se han dado cambios importantes como la eficiencia de los mercados financieros, el desarrollo del dinero electrónico y términos como equilibrio, modelo de valuación de activos de capital, entre otros. Otro aspecto importante es la racionalidad de las personas relacionando la economía con la psicología; lo que marca el inicio de las "finanzas conductuales" como lo menciona el autor Garay Anaya con la explicación de que existe una gran brecha entre un modelo ideal de comportamiento racional y el comportamiento real de los individuos donde hay influencia del contexto para la toma de decisiones.

El presente artículo de investigación informa al lector sobre temas económicos financieros para apoyar su vida cotidiana en futuras decisiones financieras con el fin proporcionar bienestar personal y familiar, explicando las finanzas conductuales, el alfabetismo financiero y el impacto en la toma de decisiones financieras, el bienestar económico y la felicidad como estrategia.

\section{Referencias}

[1] Garay Anaya, Gonzalo. (2015). Las Finanzas Conductuales, el Alfabetismo Financiero y su Impacto en la Toma de Decisiones Financieras, el Bienestar Económico y la Felicidad. Revista Perspectivas, (36), 734. Recuperado en 27 de agosto de 2018, de http://www.scielo.org.bo/scielo.php?script=sci_arttext\&pi $\mathrm{d}=$ S1994-37332015000200002\&lng=es\&tIng=es 